\title{
Developing Ethical Leadership in Health Care - Experience of Introducing Bioethics in Post Graduate Training
}

\author{
Sarosh Saleem ${ }^{1}$, Sana Tariq ${ }^{2}$ \\ ${ }^{1,2} 4^{\text {th }}$ Floor, Department of Bioethics, Shalamar Medical College Mughalpura Lahore Pakistan. \\ Department of Bioethics, Shalamar Medical and Dental College Lahore. \\ Corresponding Author: Sarosh Saleem \\ E-mail: sarosh.saleem@sihs.edu.pk; drsarosh@hotmail.com
}

\begin{abstract}
Background: Medical ethics is crucial for healthcare delivery. Shalamar Institute of Health sciences (SIHS) is the only institution in Pakistan with mandatory Bioethics training for undergraduate as well as post graduate medical trainees.

Methodology: In 2018-19 eight workshops were organized for Post-graduate trainees and feedback was obtained. All the PG trainees who participated in these workshops $(n=60)$ reported it as 'extremely useful'.

Results: The $98.3 \%$ showed satisfaction from facilitators and considered duration of workshops as adequate. The $88.3 \%$ of the PG trainees were of opinion that they would like to attend more sessions on the medical ethics in future. The major themes emerged from the qualitative analysis were: 1) Effects on practices and perspective 2) Improved knowledge about ethical issues 3) Enhanced communication skills. The teaching methodologies like the use of simulated patient, reflection and case discussion were highly appreciated by participants.

Conclusion: Bioethics training for PG-trainees will have a long-term effect on sensitizing participants towards moral issues. It provides them the necessary tools to deal with ethical, moral and religious dilemmas faced in every day practice of medicine, making them more compassionate and culturally sensitive. We share our experience with the hope that this initiative would serve as the first step of a long journey towards creating world class medical leaders in the field of ethical professionalism.
\end{abstract}

Key words: Bioethics, Post-graduate training, Ethics education.

\section{Introduction}

The knowledge and understanding of ethical and moral challenges is imperative for healthcare providers. The 21st century has witnessed rapid development of technology, research and human progress in medical science that gives rise to crucial situations where moral and cultural values collide. The pressing need for familiarity with the ethical dimensions of health care is acknowledged worldwide. United Nations Educational, Scientific and Cultural Organization (UNESCO) made ethics of science and technology one of its five priority areas [1]. However, there remains a huge gap in this area owing to lack of trained professionals as well as formal trainings. Healthcare providers and particularly physicians face many ethical challenges when dealing with patients and their families. Significance of formal ethics trainings for physicians cannot be undermined. It has been observed and reported that physicians are not very well aware of the codes 
of ethics and common ethical issues [2]. The onus of responsibility lies not only on the individual colleagues and seniors but also on the institutions to develop and encourage moral discourse (i). The institutions must foster a safe environment where ethical discourse is part of teaching and training.

Shalamar Institute of Health Sciences (SIHS) recognizes the need of structured education of medical ethics among the healthcare professionals and therefore, has taken up the responsibility to educate and train healthcare professionals in Pakistan and specifically in Punjab. The healthcare professionals shall develop skills and knowledge that can be translated into clinical practices, patient care and even health related policy making, all adding up to improve quality of healthcare provided to patients.

The Department of Bioethics was established at Shalamar Medical and Dental College (SMDC) in November 2017. The goal of Bioethics Department is to exemplify compassionate, morally and culturally sensitive environment for healthcare professionals and patients for enhancing experiences of patients and their families at SIHS and beyond.

Several training programs were started by the Department of Bioethics at SMDC and SIHS, in order to achieve the above mentioned goal. One if the most unique program was introduction of a formal Bioethics training program for Post-graduate (PG) trainees at SIHS. The objective of this training program is to disseminate knowledge of Bioethical principles and values among PG trainees and to integrate practical engagement of ethics in research and clinical practices of young physicians [3].

\section{Methodology}

This descriptive study is designed to share the experience of introducing bioethics training as a mandatory part of PG training at SIHS, Lahore and to analyze the feedback given by training participants after these training sessions.

Workshops on six different topics were designed, keeping in mind the teaching methodologies appropriate for discussing ethical issues in clinical practice and research. Teaching methodologies include case-based discussions and simulated patients along with short lectures and reflection. Case based discussions help students to recognize and effectively analyze ethical issues [4].

\begin{tabular}{|l|l|l|l|}
\hline Topics & $\begin{array}{l}\text { Objectives for Participants: } \\
\text { By the end of the workshop, } \\
\text { participants will be able to: }\end{array}$ & $\begin{array}{l}\text { Teaching } \\
\text { Methodologies }\end{array}$ \\
\hline $\mathbf{1}$ & $\begin{array}{l}\text { Confidentiality and Professional } \\
\text { Boundaries }\end{array}$ & $\begin{array}{l}\text { Describe the importance of, and } \\
\text { difference between Privacy \& } \\
\text { Confidentiality } \\
\text { Analyze ethical issues of } \\
\text { confidentiality in clinical practice } \\
\text { and research } \\
\text { Contemplate } \\
\text { boundaries in era of social media }\end{array}$ & $\begin{array}{l}\text { Short Lecture* } \\
\text { Reflection } \\
\text { Video }\end{array}$ \\
\hline $\mathbf{2}$ & $\begin{array}{l}\text { Decision making \& breaking bad } \\
\text { news }\end{array}$ & $\begin{array}{l}\text { Recognize the importance of } \\
\text { good communication in giving } \\
\text { bad information to patients or } \\
\text { families } \\
\text { Review the factors that can create } \\
\text { communication problems } \\
\text { Practice skills that can help } \\
\text { healthcare providers to improve } \\
\text { communication when giving bad } \\
\text { news }\end{array}$ & \\
\hline
\end{tabular}




\begin{tabular}{|c|c|c|c|}
\hline 3 & $\begin{array}{l}\text { Conflict of Interest-Physician } \\
\text { Pharma Interaction }\end{array}$ & $\begin{array}{l}\text { Describe Conflict of Interest in } \\
\text { Healthcare } \\
\text { Appreciate ethical aspects of } \\
\text { Physician and Pharmaceutical } \\
\text { interactions }\end{array}$ & $\begin{array}{l}\text { Short Lecture* } \\
\text { Video } \\
\text { Case Studies }\end{array}$ \\
\hline 4 & Informed consent & $\begin{array}{l}\text { Describe informed consent in } \\
\text { healthcare practice and research } \\
\text { Identify ethical considerations of } \\
\text { informed consent and human } \\
\text { dignity } \\
\text { Understand and demonstrate } \\
\text { skills to analyze ethical dilemmas } \\
\text { in clinical practice }\end{array}$ & $\begin{array}{l}\text { Case Studies } \\
\text { Short Lecture* } \\
\text { Reflection } \\
\text { Video }\end{array}$ \\
\hline 5 & End of Life Ethical Issues & $\begin{array}{l}\text { Discuss common ethical issues } \\
\text { faced at End of Life (EOL) } \\
\text { Review strategies to effectively } \\
\text { analyze ethical issues at EOL } \\
\text { Practice skills that can help } \\
\text { healthcare providers to improve } \\
\text { communication with patients and } \\
\text { families at EOL }\end{array}$ & $\begin{array}{l}\text { Case Studies } \\
\text { Short Lecture* } \\
\text { Reflection } \\
\text { Narration } \\
\text { Video }\end{array}$ \\
\hline 6 & Research Ethics & $\begin{array}{l}\text { - Identify ethical issues faced by } \\
\text { young \& seasoned researchers } \\
\text { - Analyze ethical issues in } \\
\text { research and apply principles } \\
\text { of ethics } \\
\text { - Effectively review a research } \\
\text { proposal and provide } \\
\text { feedback }\end{array}$ & $\begin{array}{l}\text { Short Lecture* } \\
\text { Video } \\
\text { Case Studies }\end{array}$ \\
\hline
\end{tabular}

\section{Table 1: Details of Workshops at SIHS}

*Short Lecture: $10-15$ min

The Department of Bioethics conducted eight workshops in a period of one year (October 2018 to October 2019). These workshops were facilitated by faculty of Bioethics along with other faculty members who narrated their clinical experiences of dealing with ethical issues at work. Two sessions each on topics of 'Confidentiality \& Professional Boundaries' and 'Breaking Bad News' were organized for different groups of PG trainees. Workshops on rest of the topics were conducted only once during the year.

The self-reported feedback forms contain the workshop title, date and the name of facilitator. It included closed ended questions about duration of workshop, feedback on facilitator and the topic using a 3 point Likert scale. The feedback form had some open ended questions about participants' expectations from the workshops, how (if) their knowledge was impacted and what would they suggest to the facilitators of the workshops. (see Annexure A)

No identifiable information such as names of the participants or their departments was mentioned on the forms. The questions on the feedback form were analyzed both qualitatively using manual method and quantitatively using SPSS version 20. The data collected was stored in the locked cabinets and password protected computers. Only the researchers were able to access it.

\section{Results}

The data was collected from 60 participants. All participants reported these workshops extremely useful on Likert scale. The time duration of workshops was found adequate by $98.3 \%(n=59)$ participants. The same number of participants reported satisfaction with the facilitation skills. 93.3\% $(n=56)$ participants acknowledged that the sessions affected their knowledge and attitudes 
towards ethical issues. 4 participants did not answer the question regarding effect on knowledge and attitude. The $88.3 \%$ of the PG trainees were of opinion that they would like to attend more sessions on the medical ethics in future while $11.7 \%$ of the opinions were missing The participants were asked if they had ever attended a Bioethics workshop or lecture. Earlier workshop trainings were mostly attended by participants at SIHS.

\section{Attended Medical Ethics lecture/workshop before}

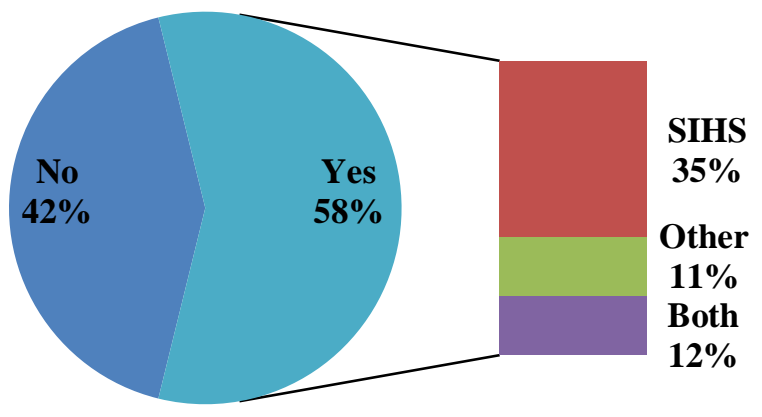

Figure 1: Participants' exposure to Bioethics lectures/trainings, in and outside SIHS

\section{Expectations from the workshop}

The question about expectations of the participants, before attending the workshop, was answered by only 17 participants. However, the responses ranged from 'gaining knowledge' to 'learning communication skills and practical resolution of ethical dilemmas'. Out of 17 responses to this question, about $41 \%$ responses were centered on theme of gaining knowledge. About $29 \%$ responses were about patient dealing and practical application in clinical practice. One respondent said, "I expected to learn about how to deal with patients in everyday life and how to communicate and transfer information to them". Another one commented, "Participants also anticipated discussion of practically faced ethical issues in clinical practice".

"..it will be helpful in my daily dealing with patients"

"..that it will cover clinical experiences related to this topic"

\section{Impact on your existing knowledge and attitudes}

The impact on knowledge after attending the workshop was also asked as an open ended question. The cumulative response expressed a positive impact of the trainings. One PG trainee commented, "The workshop helped me sort out ideas and how to deal with challenging situations.... I hope and pray that it turns me into a good physician". The comments suggested that the participants reflected on their own clinical practices: "a take home message: improve your ethical ground at individual level" and, "It helped me enhance my ethical perspective of patient management".

The participants reported a change in behavior and attitude towards patients, after these sessions. "I feel I have become more empathetic after attending the workshop."

\section{Suggestions by participants}

The themes emerging from suggestions of participants included endorsement of such trainings and recommendations to have increased number of 'mandatory' workshops for all junior faculty and trainees.

"These workshops help healthcare professionals by all means....ethics is the most ignored part in our healthcare setup.... therefore such workshops should be conducted more often to help the doctors become more empathetic".

"I personally believe that these kind of workshops should be a part of Continued Professional Development...we all lag behind in ethical aspects of patient management."

"Fruitful exercise... more of such workshops should be conducted..." 
"Such workshops need to be held more often....good platform for learning with real scenarios." The participants specifically commented on the teaching methodologies used in these workshops. A remark on simulated patients and case discussions said: "it was really beneficial for future interaction with patients". Another participant wrote: "Practice session with simulated patient was helpful... as real life situation"

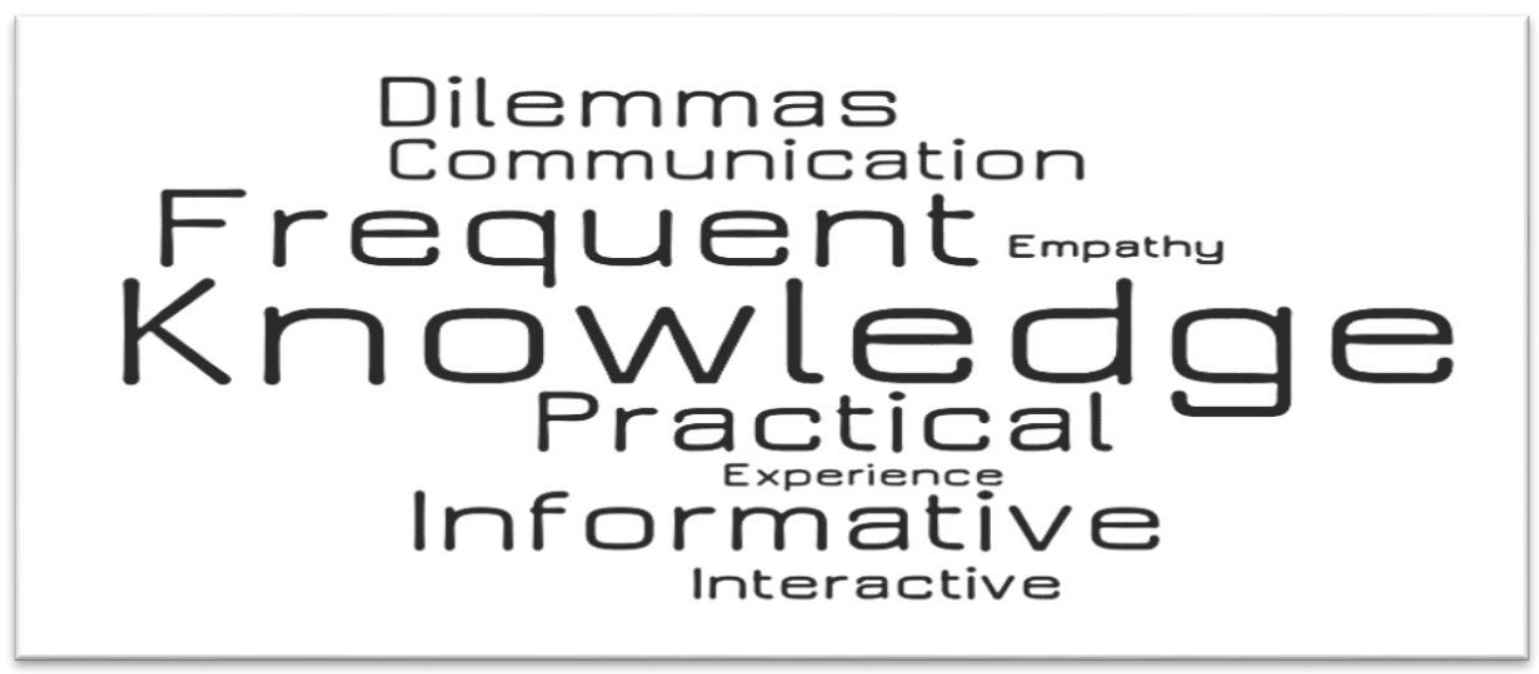

Figure 2: Words used to describe the workshops

\section{Discussion}

Bioethics education is an integral part of medical education. Physicians in training, irrespective of their field of training, require basic education of moral principles and their application in their clinical practice. Training programs around the world use various teaching as well as assessment strategies for ethics education [5-6]. Therefore, at SIHS, workshops were designed with various teaching strategies. The topics and teaching strategies were planned so as to cultivate critical thinking and reflective abilities among PG Trainees. The trainees frequently commented positively on interactive and case-based teaching sessions. Problem based teaching has been shown to be an effective strategy for ethical discourse and training [7].

Physician's communication and interpersonal skills help in obtaining the history for accurate diagnosis, explaining the patient about prognosis and giving therapeutic instructions, counseling the patients and establishing a trusting relationship [8]. Particular emphasis on communication skills of PG Trainees was given in all our workshops. The trainees reported a change in perception and understanding of 'end of life' discussions with patients and families. Some trainees regarded experience with simulated patients as meaningful, stating that will help improve their communication with their patients especially when conveying bad news. Similarly, importance of informed consent and value of the process of gaining consent, so that the patient comprehends all the information being relayed, was reported to be appreciated by the trainees. The discussions on informed consent were not limited to clinical practice but also included discussion of practices and procedures in clinical research.

Interactive learning experiences like case-based discussions and interaction with simulated patients have usually been preferred models for teaching and training Bioethics and Professionalism [9]. The participants of our workshops valued the use of videos and interactive case discussions. The cases were mostly real-life experiences of facilitators. Privacy of patients being discussed was respected by using aliases. The workshops on topic of "Confidentiality and Professional boundaries" helped the PG trainees develop understanding of critical and sensitive aspects of patients' rights. Respecting a patient's right to privacy and confidentiality is an important characteristic of medical professionalism. The assurance of maintaining privacy not only helps in building trust of the patients but also reduces risks of stigmatization in a society [10]. Therefore, 
this topic is frequently discussed with PG trainees in workshops designed by Department of Bioethics at SMDC.

A physician has a moral obligation to make decisions in the best interests of the patients. Such decisions must be transparent and without any interest of personal gain [11]. Hence, the topic of 'Conflict of Interest' is discussed with PG trainees in our workshops. The undue influence of marketing strategies adapted by pharmaceutical companies may impact practices of physicians. This is phenomenon is prevalent all over the world and has influenced the behaviors of physicians in countries like Pakistan [12]. Discussions on such attitudes versus ethical obligations of physicians are, therefore, discussed with PG trainees at SIHS. As reported by the trainees, these discussions have been helpful to them. They even mentioned in the feedback that their knowledge about such issues improved with the workshops [13].

Deliberation and appreciation of ethical issues faced by physicians cannot be effective without cultural context and social relevance of those issues. Care and health of a person cannot be discussed or described devoid of cultural and social framework [14]. Pakistan has unique and diverse socio-cultural composition. The challenges of healthcare providers and patients are, therefore, also unique to Pakistan. It is imperative that local cultural and social values be considered in ethical discourses. The cases and videos discussed in the workshops, for PG trainees, are derived from real patient experiences. The clinical decision-making in Pakistani culture is often left for physicians. The involvement of extended family, social norms and religious beliefs make 'clinical' decision-making very complex. The ethical issues at the end of life are particularly perplexing [15]. The young physicians, during their trainings have many such encounters. Our workshops aim to enable these young trainees to stride through such challenges. Another way in which these workshops facilitate these physicians is the use of narrative and reflection during the workshops. The workshop facilitators as well as participants shared their personal experiences. This experience sharing and reflective strategies make these workshops relevant to the clinical challenges. Reflection has been established as an effective teaching approach, especially in ethics education [15]. PG trainees of SIHS have emphasized in their feedback that these techniques and experience sharing by senior faculty has been beneficial for them. They would learn from those experiences to improve their dealings with patients and families.

\section{Limitations}

This is a single centered study. The data collected is limited to only those workshops that were conducted at SIHS. Involvement of other institutions and healthcare providers other than physicians should also be studied. That may help in understanding different perspectives about teaching and training ethics to healthcare providers.

The data collected in the study is limited to immediate feedback of the participants. Additional data collection after some time, about these workshops, may be significant. It would be good to find out what the participants think about the workshops after few months. They may be able to reflect on how much were they able to apply this knowledge in their clinical practice and what challenges do they face. Also, validating the feedback form will provide a useful tool.

\section{Conclusions}

Taking care of patients, making difficult decisions with them and sharing worst news of their lives can be very daunting experiences for young physicians. They must be trained to face these challenging tasks, just like they are trained in their clinical skills. Bioethics workshops designed for PG trainees at SIHS are doing that. Ethical discourse with stress on communication skills have been a major component of these trainings. The trainees have expressed their assurance in these workshops and believe that this learning experience shall impact their practices. More frequent sessions with varied teaching methodologies should be conducted for all healthcare providers so as to make them morally sensitive and confident while taking care of their patients. It is inevitable that physicians should learn practical application of their knowledge. Institutions have a great responsibility towards training of ethics and professionalism at undergraduate as well as postgraduate level to healthcare providers. 


\section{ANNEXURE A \\ FEEDBACK FORM \\ Department of Bioethics, Shalamar Medical \& Dental College, Lahore}

Workshop Title:

Date:

Facilitator/s:

1. Did you find this workshop useful?

O Yes

O Somewhat

O Not at all

2. Is the time duration for the workshop adequate?

O Yes

O No it should be increased

O No it should be decreased

3. If no, please specify why and how much increase/decrease would you want?

4. Were you satisfied with the facilitation provided by the facilitators?
O Yes
O Somewhat
O Not at all

5. If you weren't satisfied, please specify how would you want the facilitation to be improved?

6. What were your expectations from this workshop?

7. Do you feel that this workshop affected your knowledge of and attitude towards medical ethics?
O Yes
O No

8. If yes, please elaborate the way that you believe it impacted your existing knowledge and attitudes?

9. If no, please suggest changes that you want in the future workshops in order to have a positive impact on your medical ethics knowledge and your attitudes towards it?

10. Would you like to attend more workshops on medical ethics in the future?
O Yes
- No

11. Any other suggestions?

\section{REFERENCES}

1. Universal Declaration on Bioethics and Human Rights (adopted by the UNESCO General Conference). 2005.http://portal.unesco.org/en/ev.php. Accessed 10 September 2019.

2. Arun Babu T, Venkatesh C, Sharmila V. Are tomorrow's doctors aware of the code of medical ethics?. Ind J Med Ethics 2013;10(3):192-4

3. Yerramilli $\mathrm{D}$. On cultivating the courage to speak up: the critical role of attendings in the moral development of physicians in training. Hastings Cent Rep. 2014;44(5):30-2.

4. Smith S, Fryer-Edwards K, Diekema DS, Braddock $\mathrm{CH}$ 3rd. Finding effective strategies for teaching 
ethics: a comparison trial of two interventions. Acad Med 2004;79(3):265-71.

5. Merril AP. Teaching and evaluation of ethics and professionalism in Canadian family medicine residency programs. Can Fam Physician 2012;58(12):e751-6.

6. de Blacam, Catherine MD, Vercler, Christian J. MD, MA. Teaching Ethics and Professionalism in Plastic Surgery: A Systematic Review. Ann Plast Surg 2014;72(4):484-8.

7. Lin CF, Lu MS, Chung CC, YanCM. A comparison of problem based learning and conventional teaching in nursing ethics education. Nurs Ethics 2010;17(3):373-82.

8. Duffy FD, Gordon GH, Whelan G, Cole-Kelly K, Frankel R, Buffone N, et al. Assessing competence in communication and interpersonal skills: the Kalamazoo II report. Acad Med 2004;79(6):495-507.

9. Al Mahmoud T, Hashim MJ, Elzubeir MA, Branicki F. Ethics teaching in a medical education environment: preferences for diversity of learning and assessment methods. Med Educ Online 2017;22(1):1328257..

10. Dapaah JM, Senah KA. HIV/AIDS clients, privacy and confidentiality; the case of two health centres in the Ashanti Region of Ghana. BMC Med Ethics 2016;17(1):41.

11. Lichter AS. Conflict of interest and the integrity of the medical profession. JAMA 2017; 317:17256.

12. Fadlallah R, Alkhaled L, Brax H, Nasser M, Rajabbik MH, Nass H, et al. Extent of physicianpharmaceutical industry interactions in low- and middle-income countries: a systematic review. Eur J Public Health 2018;28(2):224-30.

13. Kristeva J, Moro MR, Odemark J, \& Engebretsen E. Cultural crossings of care: An appeal to the medical humanities. Medical Humanities 2017;44(1):55-8.

14. Khan RI. End of life care in Pakistan; some ethical issues J Coll Physicians Surg Pak. 2012;22(12):745-6.

15. Van den Hoven M, Kole J. Distance, dialogue and reflection: Interpersonal reflective equilibrium as method for professional ethics education. J. Moral Edu 2015;1:1-20.

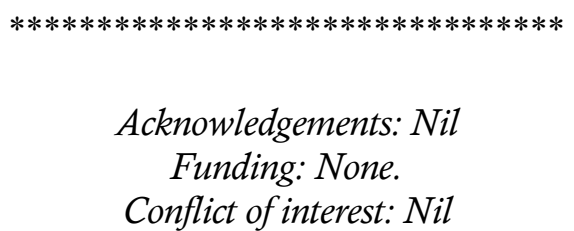

